\title{
Therapeutic Effect of Adipose Derived Stem Cells versus Atorvastatin on Amiodarone Induced Lung Injury in Male Rat
}

\author{
Gihan Ibrahim Aboul-Fotouh ${ }^{1}$, Maha Baligh Zickri ${ }^{1}$, Hala Gabr Metwally ${ }^{2}$, \\ Ihab Refaat Ibrahim ${ }^{1}$, Samaa Samir Kamar ${ }^{1}$, Wael Sakr $^{3}$ \\ Departments of ${ }^{1}$ Histology and ${ }^{2}$ Clinical Pathology, Faculty of Medicine, Cairo University, Cairo, Egypt, \\ ${ }^{3}$ Department of Plastic Surgery, Faculty of Medicine, Beni-Suef University, Beni-Suef, Egypt
}

Background and Objectives: Amiodarone (AM), a class 3 antiarrhythmic drug, has been associated with variety of adverse effects, the most serious of which is pulmonary toxicity. Ator (A) is a statin, known for their immunomodulatory and anti-inflammatory activities. Recent studies provide evidence of potential therapeutic effect of statins on lung injury. Adipose derived stem cells (ADSCs) have shown great promise in the repair of various tissues. The present study aimed at investigating and comparing the possible therapeutic effect of A and ADSCs on AM induced lung injury in albino rats.

Methods and Results: 34 adult male albino rats were divided into 5 groups: control group (Gp I), A group (Gp II) received $10 \mathrm{mg} / \mathrm{kg}$ of A orally 6 days (d)/week (w) for 4 weeks (ws), AM group (Gp III) received $30 \mathrm{mg} / \mathrm{kg}$ of AM orally $6 \mathrm{~d} / \mathrm{w}$ for 4 ws, AM\&A group (Gp IV) received AM for 4ws then A for other 4 ws and AM\&SCs group (Gp V) received AM for 4 ws then injected with $0.5 \mathrm{ml}$ ADSCs on 2 successive days intravenously (IV). Histological, histochemical, immunohistochemical and morphometric studies were performed. Group III displayed bronchiolitis obliterans, thickened interalveolar septa (IAS) and thickened vascular wall which were proven morphometrically. Increased area\% of collagen fibers and apoptotic changes were recorded. All findings regressed on A administration and ADSCs therapy.

Conclusion: Ator proved a definite ameliorating effect on the degenerative, inflammatory, apoptotic and fibrotic changes induced by AM. ADSCs administration denoted more remarkable therapeutic effect compared to A.

Keywords: Lung, Amiodarone, Ator, ADSCs

\section{Introduction}

Interstitial lung diseases (ILDs) are heterogeneous diseases that affect the lung parenchyma in a diffuse and

\footnotetext{
Accepted for publication August 12, 2014, Published online November 30, 2015 Correspondence to Maha Baligh Zickri

Department of Histology, Faculty of Medicine, Cairo University, Cairo, Egypt

Tel: +01223955078, Fax: +20235381183, +20235381760

E-mail: maha_kaah@yahoo.com

(c) This is an open-access article distributed under the terms of the Creative Commons Attribution Non-Commercial License (http://creativecommons.org/ licenses/by-nc/4.0/), which permits unrestricted non-commercial use, distribution, and reproduction in any medium, provided the original work is properly cited.
}

multicompartmental manner, being characterized by different combinations of inflammation and fibrosis. It could be idiopathic or related to known causes. Drug induced ILDs were documented in cases of bleomycin, methotrexate and AM (1).

Amiodarone is a class 3 antiarrhythmic drug, used in life threatening ventricular arrhythmia and atrial fibrillation. However, AM use has been associated with variety of adverse effects, the most serious of which is pulmonary toxicity (2). Interstitial pneumonitis can progress to potentially life-threatening pulmonary fibrosis and even death (3).

Statins, 3-hydroxy-3-methylglutaryl-coenzyme A (HMG$\mathrm{CoA})$ reductase inhibitors, known for their broad pharmacological activities including immunemodulatory and anti- 
inflammatory. Clinically, they are used for the treatment of dyslipidemia and the prevention of cardiovascular disease (4). Recent studies provide evidence of potential therapeutic effect of statins on paraquet induced lung fibrosis (5).

Adipose tissue represents an abundant and accessible source of adult stem cells with the ability to differentiate along multiple lineage pathways. ADSCs have shown great promise in the repair of various tissues including musculoskeletal system (6) and central nervous system (7).

The present study aimed at investigating and comparing the possible therapeutic effect of atorvastatin, its possible activation of endogenous stem cells and injected human ADSCs on $\mathrm{AM}$ induced lung injury in albino rat.

\section{Materials and Methods}

\section{Drugs}

Amiodarone (Cordarone): (Sanofi Corporation, Istanbul, Turkey) used as ampoules $150 \mathrm{mg} / 3 \mathrm{ml}$ dissolved in tween 80 , given at a dose of $(30 \mathrm{mg} / \mathrm{kg})$ once daily by an intragastric tube.

Atorvastatin (Ator): (E.I.P.I.Co., $10^{\text {th }}$ of Ramadan, Egypt) in the form of $10 \mathrm{mg}$ tablets. They were crushed and the required dose $(10 \mathrm{mg} / \mathrm{kg})$ was weighed using a digital scale. The required dose was dissolved in $0.5 \mathrm{ml}$ saline and given to rats once daily by an intra-gastric tube.

\section{Animals}

Thirty four adult male albino rats weighing (150 200 gm) were divided into 5 groups. The animals were bred in the Animal House of Physiology Department, Faculty of Medicine, Cairo University. Each group was kept in a separate wire cage at room temperature, fed ad libitum and allowed for free water supply. All procedures were held under ethical guidelines of animal care of Cairo University.

\section{Group I (Control group)}

\section{Eight rats were divided into}

- 2 rats, each given $0.5 \mathrm{ml}$ saline (solvent of $\mathrm{A}$ ) and other 2 rats, each given $0.5 \mathrm{ml}$ tween 80 (solvent of AM) daily orally using an intragastric tube $6 \mathrm{~d} / \mathrm{w}$ for 4 ws. The rats were left for other 4 ws without administration.

- 2 rats, each given $0.5 \mathrm{ml}$ tween 80 for 4 ws, then 0.5 $\mathrm{ml}$ saline for other $4 \mathrm{ws}$.

- 2 rats, each given $0.5 \mathrm{ml}$ tween 80 for 4 ws, then 0.5 $\mathrm{ml}$ phosphate buffer saline (PBS) (suspension of ADSCs) for 2 successive days by IV injection in the tail vein. Then, they were left for other 4 ws without PBS administration.

Group II (A group): Six rats, each received $10 \mathrm{mg} / \mathrm{kg}$ A dissolved in $0.5 \mathrm{ml}$ of saline (8), orally $6 \mathrm{~d} / \mathrm{w}$ for $4 \mathrm{ws}$.
The rats were sacrificed 4 ws following the drug cessation.

Group III (AM group): Eight rats, each received AM at a dose of $30 \mathrm{mg} / \mathrm{kg}$ (9) orally $6 \mathrm{~d} / \mathrm{w}$ for 4 ws. 2 rats were sacrificed at the end of 4 weeks for the confirmation of lung damage by examination. Using H\&E and Masson's staining, lung injury was found without an obvious increase in collagen content. The other 6 rats were left for 4 ws without AM administration or therapy. At the end of the 8 ws the rats were sacrificed.

Group IV (AM \& A group): Six rats were given AM in the same dose, by the same route and for the same duration as in group III. Then the animals were given $\mathrm{A}$ in the same dose, by the same route and for the same duration as in group II. At the end of the 8 ws the rats were sacrificed.

Group V (AM \& SCs group): Six rats were given AM in the same dose, by the same route and for the same duration as in group III. Then they were injected with 0.5 $\mathrm{ml}$ of cultured and labeled ADSCs suspended in PBS on 2 successive days in the tail vein following confirmation of lung injury (7). Stem cells were isolated from abdominal fat obtained by liposuction (10) which was performed at the General Surgery Operation Theatre, Faculty of Medicine, Beni-Suef University. Stem cell isolation, culture, labeling and phenotyping were performed at the Clinical Pathology Department, Faculty of Medicine, Cairo University. The rats were sacrificed 4 ws following stem cell therapy (SCT).

\section{Adipose Tissue Collection (11)}

The harvested adipose tissue was washed with ice-cold Hank's balanced salt solution (HBSS; Invitrogen, Carlsbad, CA, USA) and dissociated mechanically by scissors. The tissue was then digested with collagenase type II (Gibco, Gaithersburg, $\mathrm{MD}, \mathrm{USA}$ ) at $37^{\circ} \mathrm{C}$ for 40 minutes (min) and dissociated carefully with pipettes. After filtering with a $70 \mathrm{~mm}$ cell strainer (BD Biosciences, San Jose, CA, USA), the suspension was centrifuged to separate the stromal vascular fraction from the floating adipocytes.

\section{ADSCs Isolation and Culture (11)}

The precipitate was resuspended and plated onto a cell culture dish (Corning, NY, USA) at a density of 105 cells/ml in fresh Dulbecco's modified Eagle's medium (DMEM)/F-12 (Invitrogen) supplemented with 1\% penicillin/streptomycin (Sigma-Aldrich, St. Louis, MO, USA) and 10\% fetal bovine serum (FBS) (Hyclone, Logan, UT, USA). Cell cultures were maintained in a standard humidified incubator, saturated by $5 \% \mathrm{CO} 2$, at $37^{\circ} \mathrm{C}$. Twentyfour hours later, the nonadherent cells were eliminated by 
changing the culture medium. The adherent cells were expanded by serial passages, and ADSCs from 3 to 5 passages were used.

\section{Subculture (12)}

Hereafter the media were completely replaced after 3 days until putative MSC colonies were noted. The cultures were inspected daily for formation of adherent spindleshaped fibroblastoid cell colonies. Subculturing was done by chemical detachment using $0.04 \%$ trypsin or by mechanically picking fibroblastoid colonies. Later, when cell numbers allowed, expansion was done in 25 square centimeter $\left(\mathrm{cm}^{2}\right)$ or $75 \mathrm{~cm}^{2}$ tissue culture flasks. Cells were seeded at densities of $3000 \sim 25000$ cells $/ \mathrm{cm}^{2}$.

\section{Flow cytometry (13)}

Flow cytometric analyses were performed on a Fluorescence Activated Cell Sorter (FACS) flow cytometer (Coulter Epics Elite, Miami, FL, USA). Human MSCs (HMSCs) were trypsinized and washed twice with PBS. A total number of $1 \times 105$ HMSC were used for each run. To evaluate the HMSC marker profile, cells were incubated in $100 \mu 1$ of PBS with $3 \mu 1$ of CD44-FITC for $20 \mathrm{~min}$ at RT. Antibody (Ab) concentration was $0.1 \mathrm{mg} \mathrm{ml}-1$. Cells were washed twice with PBS and finally diluted in $200 \mu 1$ of PBS. The expression of surface marker was assessed by the mean fluorescence. CD44 (mesenchymal stem cell marker), CD133 (early hematopoietic \& endothelial progenitor stem cell marker) and CD45 (panleucocytic marker) were also used. The percentage (\%) of cells positive $(+\mathrm{ve})$ for CD 44 was determined by subtracting the percentage of cells stained non-specifically with isotype control antibodies.

\section{Labeling (14)}

The stem cells were labeled by incubation with ferumoxides injectable solution (25 microgramFe/ml, Feridex, Berlex Laboratories) in culture medium for 24 hours with 375 nanogram $/ \mathrm{ml}$ polylysine added 1 hour before cell incubation. Labeling was histologically assessed using Prussian's blue. After labeling, Feridex labeled HMSCs were washed in PBS, trypsinized, washed and resuspended in $0.01 \mathrm{Mol} / \mathrm{L} \mathrm{PBS}$ at concentration of $1 \times 1000000$ cells $/ \mathrm{ml}$.

\section{Cell viability analysis (15)}

Cell viability was done using trypan blue dye exclusion test. It is based on the principle that live cells possess intact cell membranes that exclude certain dyes, such as trypan blue, whereas dead cells do not. The viable cell will have a clear cytoplasm whereas a nonviable cell will have a blue cytoplasm.

Histological Study: The animals were sacrificed under intraperitoneal anesthesia with sodium pentobarbital (100 $\mathrm{mg} / \mathrm{kg}$ body weight) (16) at the end of various durations previously mentioned. Lung specimens were obtained by performing a ventral midline incision, exposure, removal and fixation in $10 \%$ formol saline for 48 hours. Paraffin blocks were prepared and $5 \mu \mathrm{m}$ thick sections were subjected to hematoxylin and eosin (H\&E) (17) and Masson's trichrome stain (18).

Histochemical Study: Prussian's blue $(\mathrm{Pb})$ stain for demonstration of iron oxide labeled ADSCs (19).

Immunohistochemical Study: Caspase $3 \mathrm{Ab}$ to detect apoptotic cells (20) and CD44 immunostaining for detecting endogenous and exogenous SCs (21) were used. Ready to use rabbit polyclonal caspase 3 (CPP32) Ab-4 IgG (RB-1197-R7, Thermo Fisher Scientific; Fremont, USA) and ready to use rabbit polyclonal CD44 Ab; IgG (IW-PA1021, IHC World) were used. Application of the primary (1ry) antibodies (Abs) was followed by incubation in the humidity chamber for $60 \mathrm{~min}$ at room temperature. Tonsil was used as +ve control specimens for both caspase 3 and CD44. On the other hand, one of the lung sections was used as a negative ( - ve) control by passing the step of applying the 1ry antibody.

Morphometric Study: Using Leica Qwin 500 LTD image analysis (Cambridge, UK), assessment of the thickness of IAS and that of the wall of the pulmonary vessels indicated by the distance were performed in $\mathrm{H} \& \mathrm{E}$ stained sections. The measurements were done in 10 low power fields using interactive measurements menu. In addition, the area $\%$ of collagen fibers in Masson's trichrome stained sections, that of caspase $3+$ ve cells and that of CD44 +ve cells were recorded in immunostained sections. The measurements were done in 10 high power fields using binary mode.

Statistical Analysis: Quantitative data were summarized as means and standard deviations and compared using analysis of variance (ANOVA) followed by post-Hoc analysis (Tukey test). p-values $<0.05$ were considered statistically significant. Calculations were made on statistical package of social science (SPSS) software, version 16.

\section{Results}

No deaths were observed in all rats.

\section{Hematoxylin and Eosin stained lung sections}

Lung sections of control rats (Gp I) revealed normal lung parenchyma with preserved architecture of bron- 
chioles, alveolar sacs, alveoli, IAS, pulmonary venules and arterioles (Fig. 1A). The bronchioles were lined by columnar cells and domed shaped Clara cells (Fig. 1B). Alveoli and alveolar sacs were lined mainly by type I pneumocytes. Type II pneumocytes displayed rounded nuclei and foamy cytoplasm. The IAS exhibited pulmonary capillaries (Fig. 1C).

Amiodarone group (Gp III) exhibted patchy distribution of variable changes affecting lung parenchyma and distortion of occasional bronchioles and marked thickening of IAS (Fig. 1D). Obvious thickening of the wall of vessels and mononuclear aggregates were also detected (Fig. 1E). Close observation showed some bronchioles displaying partially obliterated lumens, shed cellular debris, stratification of the bronchiolar lining epithelium, some cells constituting dark nuclei and congested vessels (Fig. 1F). Some fields recruited thickened IAS with multiple fibroblasts surrounded by collagen deposition and lymphocytic infiltration (Fig. 1G). Multiple pneumocytes type II and few type I were noted in the lining of alveoli (Fig. 1H).

Rat lung sections of AM\& A group (Gp IV) revealed thickening of some IAS, fewer shed cells (Fig. 2A) and focal stratification of the bronchiolar lining epithelium with when compared to Gp III (Fig. 2B). Numerous type I pneumocytes and fewer type II pneumocytes were detected
(Fig. 2C).

In ADSCs therapy group ( $\mathrm{Gp} \mathrm{V}$ ), multiple fields were comparable to $\mathrm{Gp}$ I displaying patent bronchioles, alveoli and alveolar sacs. Few fields demonstrated some thickened IAS and few shed epithelial cells in the lumen of occasional bronchioles. Congestion of blood vessels was evident (Fig. 2D). Close observation displayed few round infiltrating cells in the thickened IAS, partial thickening of the wall of blood vessels and multiple spindle cells in the lumen of occasional vessels (Fig. 2E). More numerous type I pneumocytes and fewer type II pneumocytes were found by closer observation (Fig. 2F).

\section{Masson's trichrome stained lung sections}

Fine collagen fibers were found in the IAS, the adventitia of bronchioles and that of venules of control rats (Fig. 3A). While in Gp III, different fields of lung sections showed increased dense collagen fibers in obviously thickened IAS, around bronchioles and around congested blood vessels (Fig. 3B). Group IV and Gp V revealed minimal collagen fibers in the IAS, the adventitia of bronchioles and that of vessels (Fig. 3C and D).

Ator group (Gp II) lung sections stained histologically by H\&E and Masson's trichrome stains revealed picture similar to that of Gp I.

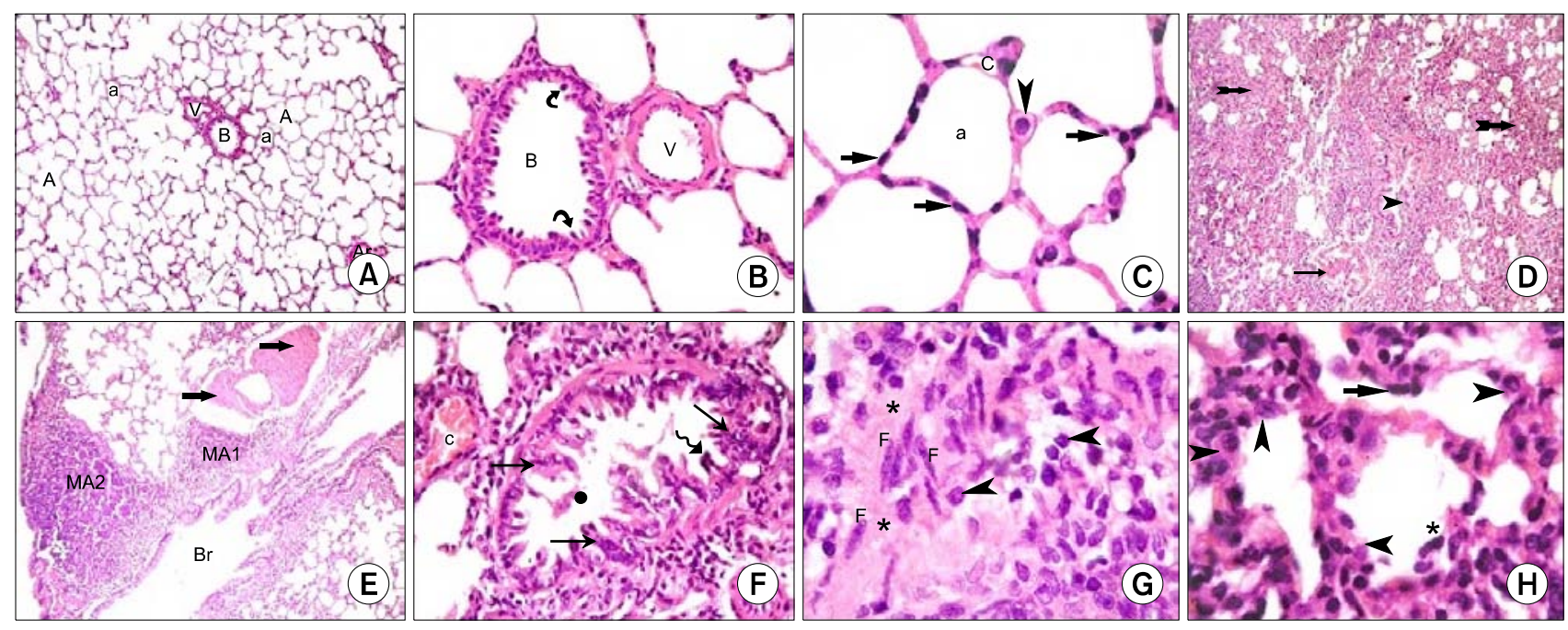

Fig. 1. Lung sections of control rats (H\&E) showing (A): a bronchiole (B), a venule (V), an arteriole (ar), alveoli (a), alveolar sacs (A) and IAS (I) $(\times 100)$, (B): a blood vessel $(V)$ and a bronchiole (B) lined by columnar cells and Clara cells $(\boldsymbol{\curvearrowright})(\times 400)(C)$ : alveoli (a) lined mainly by type I pneumocytes $(\rightarrow)$. Note few type II pneumocytes $(\longrightarrow)$ and pulmonary capillaries (c) $(\times 1000)$. Lung sections in Gp III (H\&E) showing (D): obvious thickening of multiple IAS $(\vec{\longrightarrow})$, a distorted bronchiole $(\boldsymbol{)})$ and partial thickening of the wall of a venule $(\rightarrow)(\times 100)$, (E): two peribronchial mononuclear aggregates, (MA1) and (MA2). Note obvious thickening of the wall of a vessel $(\rightarrow)$ $(\times 100)(\mathrm{F})$ : stratification of the lining epithelium $(\rightarrow)$, shed cellular debris $(*)$ in the lumen of a bronchiole, a congested vessel (c). Note the lining cells with dark nuclei $(\mathbf{4})(\times 400)$. (G): thickened IAS harboring multiple fibroblasts $(\mathrm{F})$ surrounded by collagen deposition $(*)$. Note multiple infiltrating cells $(\longrightarrow)(\mathrm{H})$ : multiple type II pneumocytes $(\longrightarrow)$ and few type I pneumocytes $(\rightarrow)$. Note shed cells $(*)(\times 1000)$. 


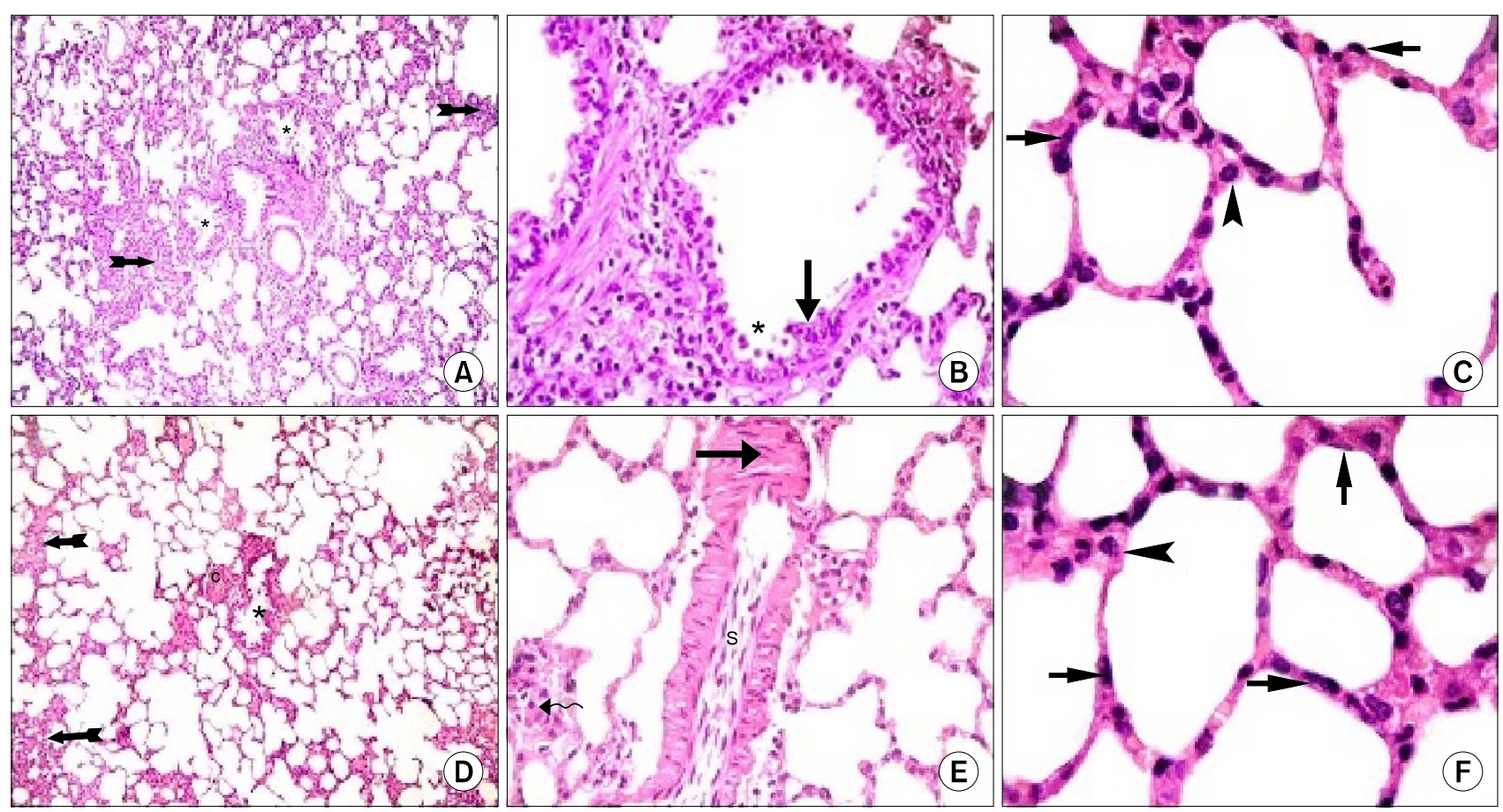

Fig. 2. Rat lung sections in Gp IV (H\&E) showing (A): 2 bronchioles with few shed epithelial cells $(*)$ in their lumens and thickening of some IAS $(\rightarrow)(\times 100),(B)$ : focal stratification of the bronchiolar lining epithelium $(\rightarrow)$ and few shed cells $(*)(\times 400)(C)$ : numerous type I pneumocytes $(\rightarrow$ ) and fewer type II pneumocytes $(\longrightarrow)(\times 1000)$. In Gp V showing (D): a bronchiole with few shed epithelial cells in the lumen $(*)$ and few thickened IAS $(\longrightarrow)$. Note a congested vessel $(c)(\times 100),(E)$ : multiple spindle cells $(S)$ in the lumen of a vessel. Note partial thickening $(\rightarrow)$ of its wall and few round infiltrating cells in the IAS $(\mathbf{a})(\times 400)$ and (F): numerous type I pneumocytes $(\rightarrow$ ) and fewer type II pneumocytes $(\longrightarrow)(\times 1000)$.

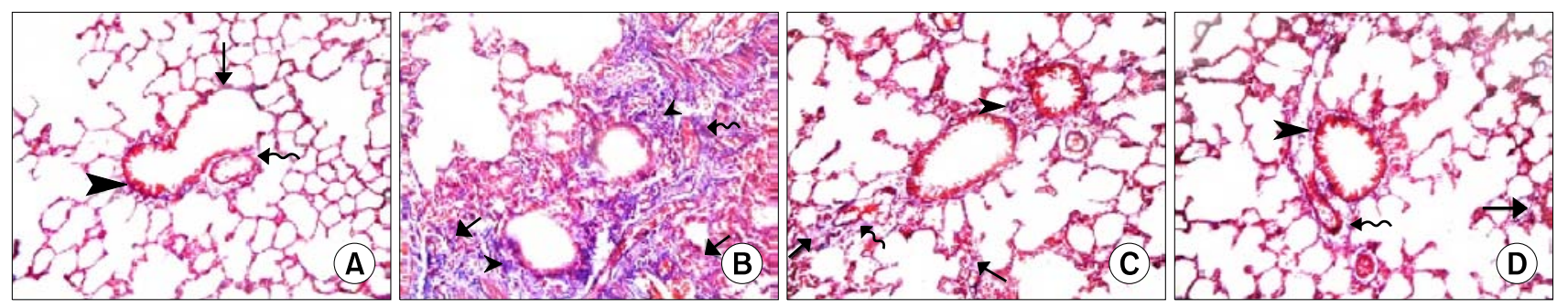

Fig. 3. (A): Lung sections in Gp I showing fine collagen fibers in the IAS $(\rightarrow)$, in the adventitia of a bronchiole $(\longrightarrow)$ and that of a venule (מ)). (B): In Gp III showing dense collagen fibers deposition in thickened IAS $(\rightarrow$ ), around bronchioles $(\rightarrow)$ and around congested blood

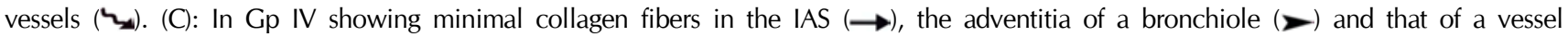

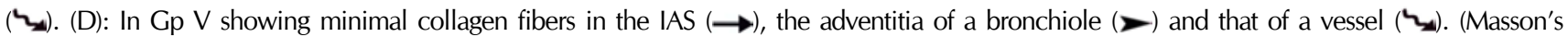
trichrome, $\times 200)$.

\section{Prussian's blue stained lung section:}

Rat lung sections in Gp I revealed -ve staining with $\mathrm{Pb}$ in the bronchioles, alveoli and IAS (Fig. 4A). Group V showed multiple $\mathrm{Pb}+\mathrm{ve}$ cells inside and surrounding congested blood vessels (Fig. 4B) and in thickened IAS (Fig. 4C).

\section{Caspase 3}

Almost -ve immunoreaction for caspase 3 was observed in Gp I with few immunostained + ve cells found in the epithelial lining of alveoli and occasional bronchioles (Fig. $5 \mathrm{~A})$. Lung sections of Gp III revealed multiple + ve cells in the epithelial lining of alveoli, alveolar sacs and in thickened IAS (Fig. 5B). While in Gp IV some fields displayed few + ve cells in the lining epithelium of few alveoli, few IAS and occasional alveolar sacs (Fig. 5C). In Gp $\mathrm{V}$, few fields with occasional + ve cells in the epithelial lining of occasional alveoli and in the epithelial lining and 

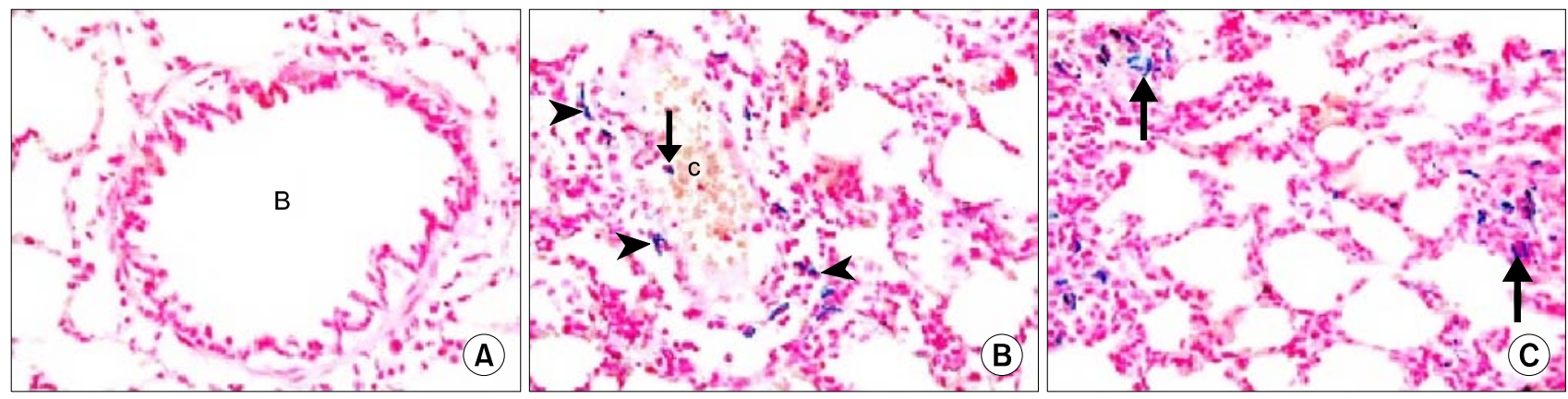

Fig. 4. (A): In Gp I showing -ve staining with $\mathrm{Pb}$ in a bronchiole (B), alveoli and IAS. In Gp V showing (B): multiple Pb + ve cells surrounding $(\rightarrow)$ and inside $(\rightarrow)$ a congested blood vessel $(\mathrm{c}),(\mathrm{C})$ : multiple $\mathrm{Pb}+$ ve cells $(\rightarrow)$ in thickened IAS $(\mathrm{Pb}, \times 400)$.

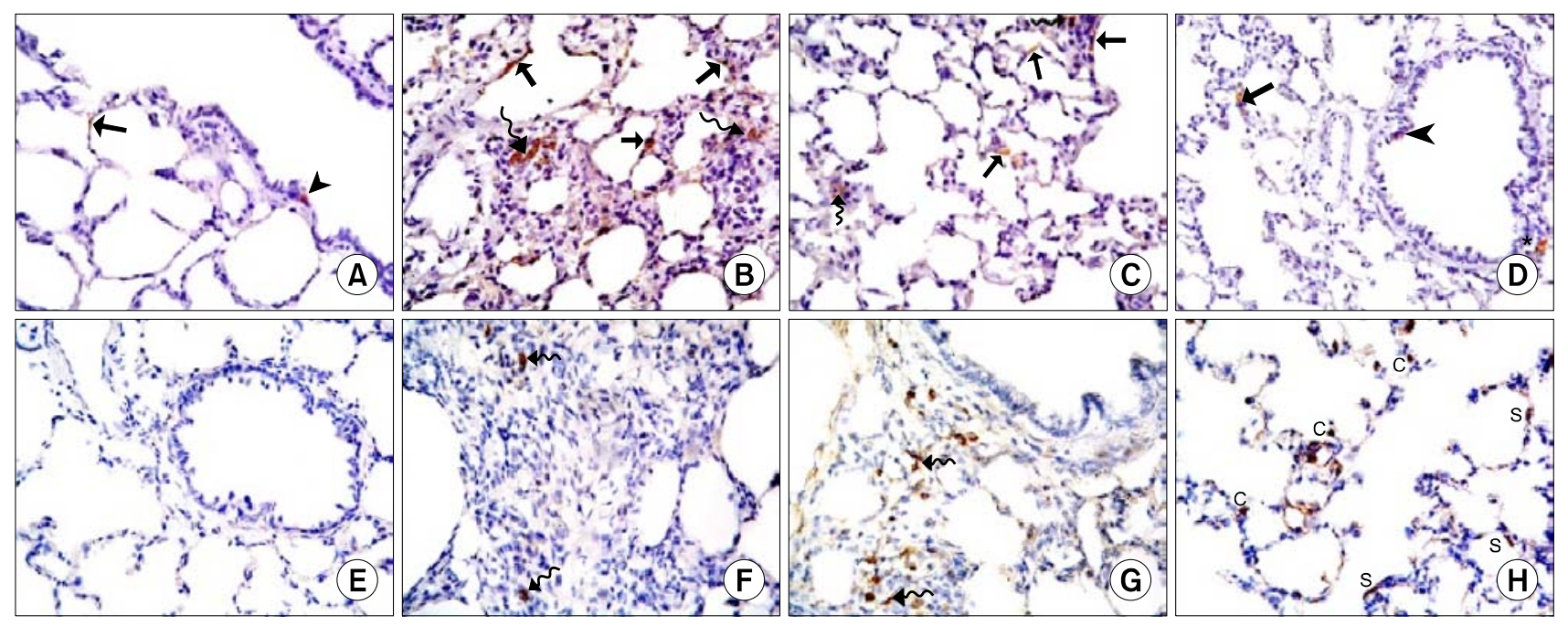

Fig. 5. Caspase 3 immunostaining $(\times 400)$ lung sections $(A)$ : in $G p$ I showing an immunostained + ve cell among the epithelial lining of an alveolus $(\rightarrow$ ) and another + ve cell in the lining of a bronchiole $(\longrightarrow$ (B): In Gp III showing multiple +ve cells in the epithelial

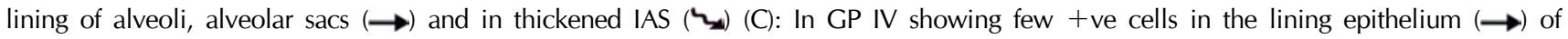
2 alveoli, alveolar sac and in 2 IAS (מצ). (D): In GP V showing few + ve cells in the lining epithelium ( $>$ ) and adventitia (*) of a bronchiole. Note $a+$ ve cell in the lining epithelium of an alveolus $(\rightarrow)$. CD44 immunostaining $(\times 400)$ lung sections $(E)$ : in Gp I showing - ve CD44 immunostaining among the epithelium lining a bronchiole, alveoli and alveolar sacs. (F): In Gp III showing few CD44 +ve spindle

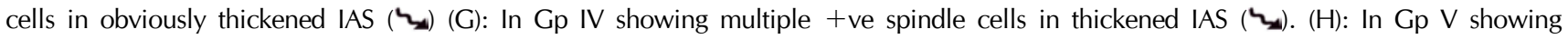
multiple + ve cuboidal cells (C) and +ve spindle cells (S) among the epithelial lining of alveoli and alveolar sacs.

adventitia of occasional bronchioles were demonstrated (Fig. 5D).

\section{44}

Negative CD44 immunostaining among bronchioles, alveoli and alveolar sacs was observed in control rats (Fig. 5E). Group III recruited few CD44 + ve spindle cells in obviously thickened IAS (Fig. 5F). Group IV revealed some fields with multiple + ve spindle cells in few thickened IAS (Fig. 5G). Group V showed multiple +ve cuboidal and spindle cells among the epithelial lining of alveoli and alveolar sacs (Fig. 5H).

Ator group lung sections stained immunohistochemi- cally by caspase 3 and CD44 revealed picture similar to that of Gp I.

\section{Morphometric results (Table 1 and Fig. 6)}

\section{Discussion}

The present study investigated and compared the possible therapeutic effect of atorvastatin and ADSCs on AM induced lung injury in albino rat. Definite amelioration of the AM induced changes in response to A and ADSCs therapy was evidenced by histological, histochemical, immunohistochemical and morphometric results. 
Table 1. The mean values of the thickness of IAS, thickness of blood vessels wall, the area $\%$ of collagen fibers and area \% of caspase 3 and CD44 + ve cells $( \pm \mathrm{SD})$

\begin{tabular}{cccccc}
\hline Groups & $\begin{array}{c}\text { Mean Thickness } \\
\text { of IAS } \pm \text { SD }\end{array}$ & $\begin{array}{c}\text { Mean Thickness of } \\
\text { blood vessels wall } \pm \text { SD }\end{array}$ & $\begin{array}{c}\text { Mean area \% of } \\
\text { collagen fibers } \pm \text { SD }\end{array}$ & $\begin{array}{c}\text { Mean area \% of caspase } 3 \text { Mean area o of CD44 } \\
+ \text { ve cells } \pm \text { SD }\end{array}$ & $\begin{array}{c}\text { Me cells } \pm \text { SD } \\
+ \text { ve }\end{array}$ \\
\hline Gp I & $3.20( \pm 0.74)$ & $11.67( \pm 0.52)$ & $5.19( \pm 0.92)$ & $3.52( \pm 0.47)$ & - \\
Gp II & $3.94( \pm 0.56)$ & $11.64( \pm 1.33)$ & $5.08( \pm 0.94)$ & $3.51( \pm 0.42)$ & - \\
Gp III & $19.24( \pm 4.97)^{*}$ & $61.69( \pm 14.13)^{*}$ & $38.36( \pm 6.14)^{\#}$ & $17.37( \pm 1.53)^{\gamma}$ & $2.89( \pm 0.27)$ \\
Gp IV & $8.85( \pm 2.05)^{\ominus}$ & $21.62( \pm 3.04)^{\theta}$ & $8.36( \pm 2.02)$ & $5.85( \pm 0.61)^{\vee}$ & $5.28( \pm 0.74)^{\square}$ \\
Gp V & $3.96( \pm 1.1)$ & $10.44( \pm 3.72)$ & $5.21( \pm 1.24)$ & $3.84( \pm 0.34)$ & $7.11( \pm 0.56)^{\Omega}$ \\
\hline
\end{tabular}

*Significant increase compared to Gp I, II, IV and V.

${ }^{\ominus}$ Significant increase compared to Gp I, II and V.

"Significant increase compared to Gp I, II, IV and V.

${ }^{\gamma}$ Significant increase compared to Gp I, II, IV and V.

ignificant increase compared to Gp I, II and V.

${ }^{\Omega}$ Significant increase compared to Gp III and Gp IV.

$\square$ Significant increase compared to Gp III.
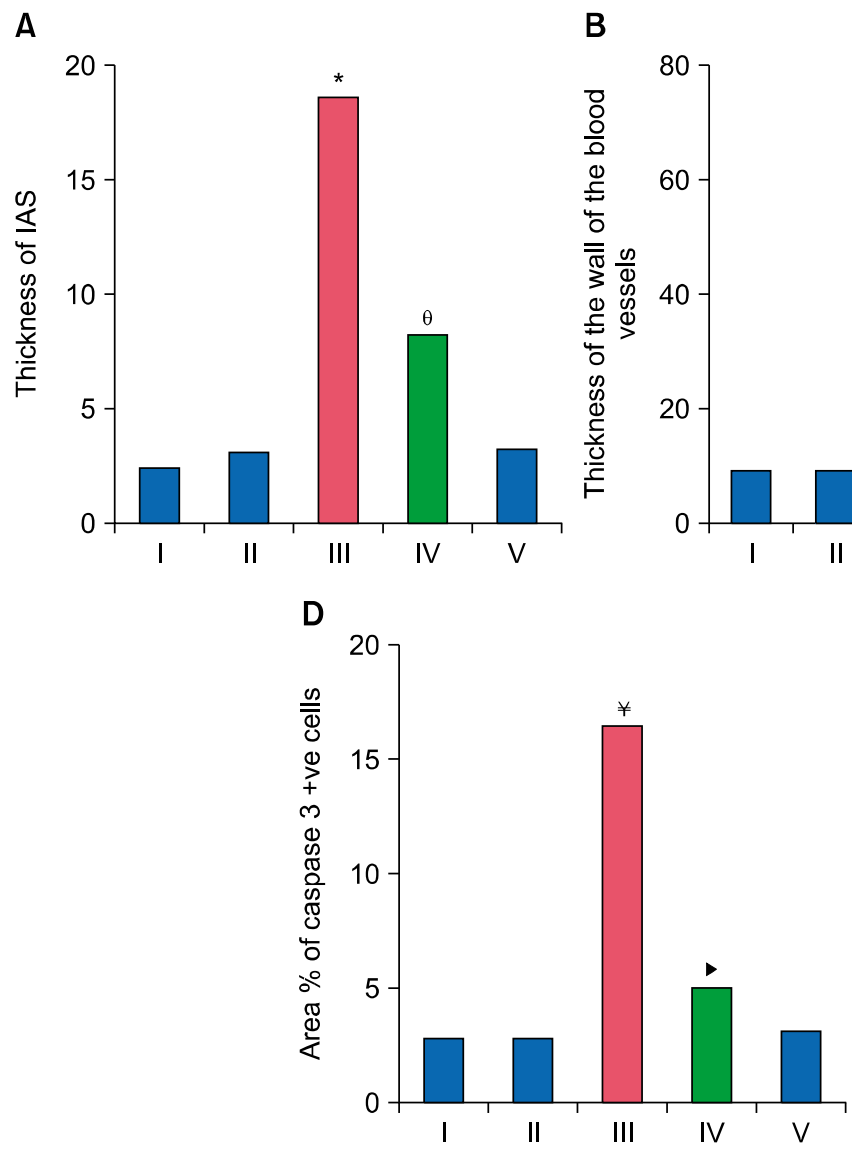

\section{B}

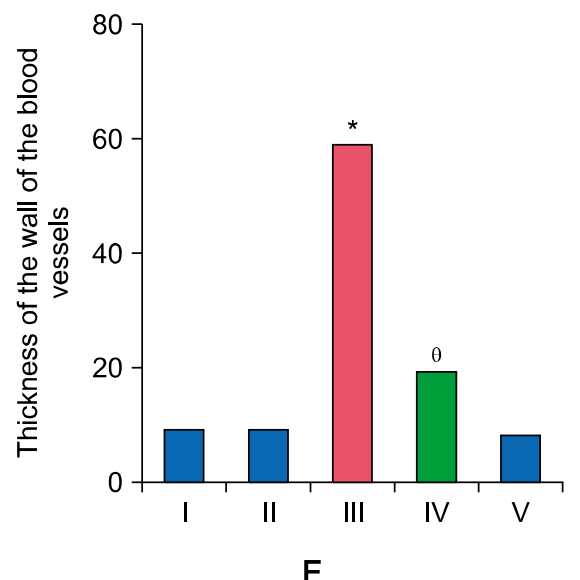

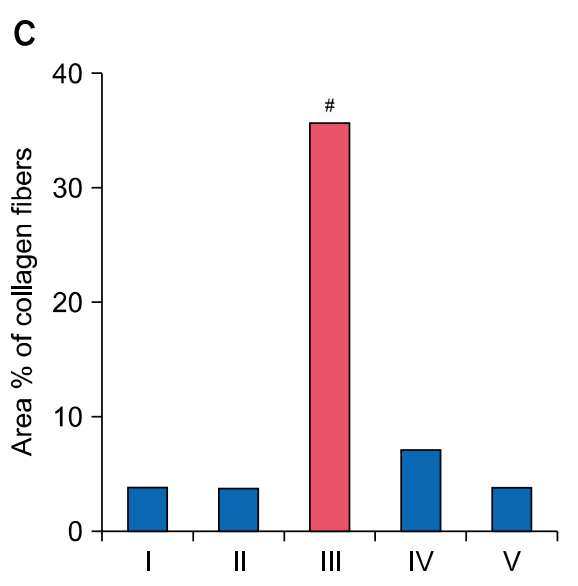

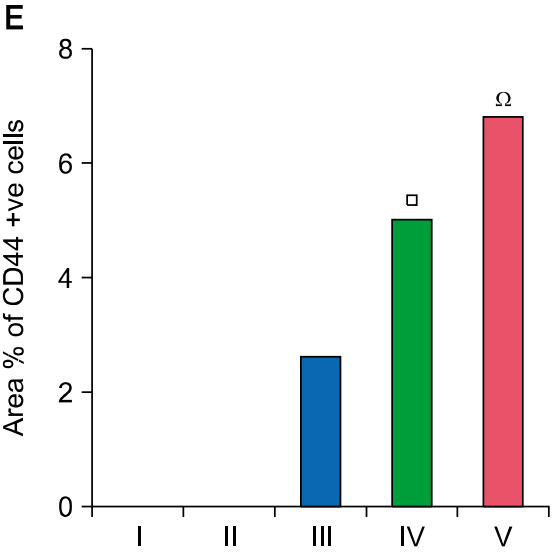

Fig. 6. Histogram comparing (A): the mean values of thickness of IAS in the control and experimental groups, (B): the mean values of thickness of wall of blood vessels in the control and experimental groups, $(\mathrm{C})$ : the mean values of area \% of collagen fibers in the control and experimental groups, (D): the mean values of area \% of caspase $3+$ ve cells in the control and experimental groups, (E): the mean values of area \% of CD44 +ve cells in the control and experimental groups.

Amiodarone administration resulted in almost complete loss of normal lung architecture with partial obliteration of the lumen of bronchioles by shed epithelial cells or oc- casionally caused complete distortion of the bronchioles. Stratification and projections of lining epithelium of some bronchioles were evident with some cells constituting dark 
nuclei. Barker et al. (22) referred the occurrence of obliterative bronchiolitis to the injury of bronchiolar epithelium and inflammation of subepithelial structures causing excessive fibroproliferation, which is due to improper tissue repair and ineffective epithelial regeneration.

Mononuclear aggregates were detected in the wall of bronchi disrupting. Grommes and Soehnlein (23) postulated that the influx of inflammatory cells into the interstitium and the bronchoalveolar space is considered an important role in the progression of lung injury. They are recruited from the circulation when local defenses are overwhelmed.

Marked increase in the thickening of IAS was confirmed by morphometric assessment of the mean thickness of IAS. Mononuclear infiltrating cells, multiple fibrobasts and extensive increase in collagen deposition were evident in the thickened IAS. The increased mean area $\%$ of collagen deposition in the lung interstitium was significant. Shroff et al. (24) displayed that oxidative stress contributes in the fibrogenesis by inducing genetic overexpression of fibrogenic cytokines such as transforming growth factor beta (TGF-beta), connective tissue growth factor (CTGF/CCN2), and platelet-derived growth factor (PDGF). These agents stimulate the differentiation of fibroblasts from mesenchymal, epithelial and endothelial cells with increased synthesis and deposition of collagen. ValchevaKuzmanova et al. (25) explained that the damaged bloodalveolar barrier and increased permeability of pulmonary epithelium and endothelium cause extravasation of plasma proteins. The latter changes can be related to the accumulation of the tissue exudates found in the present study.

Obvious thickening of the vascular wall was confirmed by a significant increase in the mean thickness of the wall of the blood vessels. In addition, congestion were noted. This can be referred to the development of pulmonary hypertension. Lee et al. (26) stated that vascular remodeling, developing after injury, is characterized by endothelial cell activation, inflammatory cell infiltration, proliferation of smooth muscle cells and augmented deposition of collagen in the vessel wall. The change in the collagen/ elastin ratio affects the mechanics of the blood vessels and increases arterial stiffness.

Multiple pneumocytes type II and few type I were noted in the lining of the alveoli. Using Tc-99m scintigraphy, Gumuser et al. (27) found that the major area of damage caused by AM is alveolar pneumocyte type I and pulmonary capillary endothelial cells. Pneumocyte type I damage is followed by pneumocyte type II hyperplasia and dysplasia.

Multiple caspase $3+$ ve cells were detected in the epi- thelial lining of bronchioles, alveoli, alveolar sacs and in thickened IAS of Gp III. The area \% of caspase 3 +ve cells in Gp III was significantly increased. Selman et al. (28) displayed that studies on human showed high rates of apoptosis and increased levels of pro-apoptotic markers in alveolar epithelial cells. However, adjacent fibroblasts/ myofibroblasts expressed antiapoptotic proteins and are relatively resistant to apoptosis.

As regards rats treated with $\mathrm{A}$, lung sections revealed fewer shed cells in the lumen of bronchioles and stratification of the bronchiolar lining epithelium. Thickening of some IAS was detected. More numerous type I pneumocytes and fewer type II pneumocytes were detected when compared to Gp III. This can be explained by the pleiotropic effects of statins including anti-inflammatory and anti oxidant effects besides their main cholesterol lowering effect.

Statins act as antiinflammatory substance via activating the expression of peroxisome proliferator activated receptor (PPAR) proteins, which mediate antiinflammatory effects (29). Khodayar et al. (30) approved the anti-inflammatory and antioxidant effect of statins by decreasing malondialdehyde levels (marker of lipid peroxidation).

Significant decrease in the mean thickness of the vascular wall was found compared to GP III. Zhang et al. (31) stated that A reversed pulmonary hypertension and vascular remodeling. It decreased the proliferation of smooth muscle cells of blood vessels and the vascular wall thickness and improved the vascular endothelial functions.

Minimal collagen fibers were detected in the IAS, the adventitia of bronchioles and that of the blood vessels in the rat lung sections treated with $\mathrm{A}$. The mean area \% of collagen fibers was significantly decreased when compared to AM treated group. This demonstrates the antifibrotic role of ator which was in agreement with $\mathrm{Zhu}$ et al. (8), who investigated the antifibrotic potential of ator against lung fibrosis. They found that ator suppressed the production of inducible nitric oxide synthase (iNOS) expressed in pulmonary fibrosis of both animal models and humans. Malekinejad et al. (5) attributed the anti-inflammatory and antifibrotic effects of ator to the regulation of transforming growth factor (TGF)- $\beta 1$ expression, which plays a key role in fibrosis of the various organs including pulmonary fibrosis.

Caspase 3 immunostaining of Gp IV revealed some fields exhibiting few immunostained + ve cells in the lining epithelium of few alveoli and few IAS. Comparing the mean values of $\%$ of caspase $3+$ ve cells in A treated group to AM group, it was significantly decreased. Chen et al. (32) reported decreased apoptotic rate in A treated 
rats evidenced by flow cytometry analysis. Western blot additionally displayed that atorvastatin induced up regulation of anti-apoptosis protein Bcl-2.

In SCT group (Gp V), multiple fields were comparable to Gp I displaying patent alveoli, alveolar sacs and bronchioles. Few fields demonstrated few shed cells in the lumen of occasional bronchioles, some thickened IAS with few round infiltrating cells and partial thickening of the wall of blood vessels. Adult SCs have been widely applied as treatment to many diseases. The ease of harvest, expansion and potency of ASCs make them attractive candidates for cell therapy. In addition they display remarkable pleiotropic properties, including anti-inflammation, antifibrosis, anti-apoptosis, angiogenesis and growth factor production. Ghasemi (33) proved the neuroprotection role of human ADSCs by immunomodulation and reducing the inflammatory responses.

Multiple spindle cells in the lumen of blood vessels and congestion were noted. Increased vascularity and congestion with SCT are very essential factors in the equation of regeneration. Abd El Azeem et al. (34) proved that the congestion and new vessels formation induced by SCT is associated with better tissue healing. More numerous type I pneumocytes and fewer type II pneumocytes were found compared to Gp III and Gp IV. This could be explained by the effectiveness of regeneration by SCT. Linero and Chaparro (35), demonstrated that, the secretion of bioactive factors and cytokines has an important role in MSC mediated paracrine activity and stimulate tissue regeneration.

The collagen fibers in Gp V were minimally detected in the IAS, the adventitia of bronchioles and that of vessels compared to Gp III and Gp IV. It was confirmed by the assessed area\% of collagen fibers which was comparable to the Gp I and proved the benefit of ASCs in the prevention of fibrosis. Castiglione et al. (36) stated that, the early application of ASCs prevents the formation of fibrosis and elastosis.

Few fields displayed occasional caspase $3+$ ve cells in the epithelial lining of occasional alveoli, in the epithelial lining and adventitia of occasional bronchioles with significant decrease in the area \% of caspase 3 +ve cells. Wang et al. (37) suggested that human ADSCs display antiinflammatory and antiapoptotic effects by primarily paracrine actions and releasing protective factors. Besides, they replace the damaged cells by differentiated stem cells.

Multiple Prussian's blue + ve cells were detected inside and surrounding congested blood vessels besides in thickened IAS. Albersen et al. (38) postulated that following systemic administration of human ADSCs, they settled in the injured tissues of experimental rats. This cell recruit- ment is essential for establishing beneficial effects of cell therapy, including enhanced functional and structural outcomes.

In Gp III, few CD44 + ve spindle cells were seen in obviously thickened IAS while in Gp IV some fields with multiple spindle cells in few thickened IAS were noted. In $\mathrm{Gp} \mathrm{V}$, multiple + ve cuboidal and spindle cells were observed among the epithelial lining of alveoli and alveolar sacs. The expression of CD44 surface marker, a cell adhesion molecule that acts as a receptor for hyaluronic acid, is characteristic of MSCs (39).

The increased area \% of CD44 + ve cells in Gp V was significant when compared with Gp III and Gp IV. Studies in animal models have demonstrated the ability of transplanted MSCs to engraft and regenerate injured tissues, in addition to increasing mobilization of the endogenous stem cells (40).

\section{Conclusion}

The present study indicated definite degenerative and inflammatory changes affecting the bronchioles, the bronchi and the lining epithelium of alveoli and alveolar sacs induced by AM administration. Confirmed apoptotic changes were also evident. In addition, increased dense collagen deposition was detected besides thickening of the pulmonary vessels denoting possibility of pulmonary hypertension. On the other hand, A proved a definite ameliorating effect on the degenerative, inflammatory, apoptotic and fibrotic changes induced by AM. ADSCs administration denoted a remarkable therapeutic effect compared to A.

\section{Potential Conflict of Interest}

The authors have no conflicting financial interest.

\section{References}

1. Meyer KC. Diagnosis and management of interstitial lung disease. Transl Respir Med 2014;2:1-13

2. Garg J, Agrawal N, Marballi A, Agrawal S, Rawat N, Sule S, Lehrman SG. Amiodarone induced pulmonary toxicity: An unusual response to steroids. Am J Case Rep 2012; 13:62-65

3. Mankikian J, Favelle O, Guillon A, Guilleminault L, Cormier B, Jonville-Béra AP, Perrotin D, Diot P, MarchandAdam S. Initial characteristics and outcome of hospitalized patients with amiodarone pulmonary toxicity. Respir Med 2014;108:638-646

4. Minder CM, Blaha MJ, Horne A, Michos ED, Kaul S, Blumenthal RS. Evidence-based use of statins for primary prevention of cardiovascular disease. Am J Med 2012;125: 
440-446

5. Malekinejad H, Mehrabi M, Khoramjouy M, RezaeiGolmisheh A. Antifibrotic effect of atorvastatin on paraquat-induced pulmonary fibrosis: role of PPAR $\gamma$ receptors. Eur J Pharmacol 2013;720:294-302

6. Labusca L, Zugun-Eloae F, Nacu V, Mashayekhi K. Adipose derived stem cells for musculoskeletal regeneration: recent patents and future perspectives. Regen Med 2013;3:132-147

7. Tajiri N, Acosta SA, Shahaduzzaman M, Ishikawa $H$, Shinozuka K, Pabon M, Hernandez-Ontiveros D, Kim DW, Metcalf C, Staples M, Dailey T, Vasconcellos J, Franyuti G, Gould L, Patel N, Cooper D, Kaneko Y, Borlongan CV, Bickford PC. Intravenous transplants of human adipose-derived stem cell protect the brain from traumatic brain injury-induced neurodegeneration and motor and cognitive impairments: cell graft biodistribution and soluble factors in young and aged rats. J Neurosci 2014;34:313326

8. Zhu B, Ma AQ, Yang L, Dang XM. Atorvastatin attenuates bleomycin-induced pulmonary fibrosis via suppressing iNOS expression and the CTGF (CCN2)/ERK signaling pathway. Int J Mol Sci 2013;14:24476-24491

9. Madkour NK, Ahmed M. Amelioration of amiodarone-induced lung fibrosis in rats by grape seed extract. J Appl Sci Res 2013;9:3698-3707

10. Gnanasegaran N, Govindasamy V, Musa S, Kasim NH. Different isolation methods alter the gene expression profiling of adipose derived stem cells. Int J Med Sci 2014;11: 391-403

11. Ma T, Gong K, Ao Q, Yan Y, Song B, Huang H, Zhang $\mathrm{X}$, Gong Y. Intracerebral transplantation of adipose-derived mesenchymal stem cells alternatively activates microglia and ameliorates neuropathological deficits in Alzheimer's disease mice. Cell Transplant 2013;22 Suppl 1:S113-S126

12. Koch TG, Heerkens T, Thomsen PD, Betts DH. Isolation of mesenchymal stem cells from equine umbilical cord blood. BMC Biotechnol 2007;7:26-34

13. Wei Y, Gong K, Zheng Z, Wang A, Ao Q, Gong Y, Zhang $\mathrm{X}$. Chitosan/silk fibroin-based tissue-engineered graft seeded with adipose-derived stem cells enhances nerve regeneration in a rat model. J Mater Sci Mater Med 2011;22: 1947-1964

14. Kraitchman DL, Heldman AW, Atalar E, Amado LC, Martin BJ, Pittenger MF, Hare JM, Bulte JW. In vivo magnetic resonance imaging of mesenchymal stem cells in myocardial infarction. Circulation 2003;107:2290-2293

15. Strober W. Trypan blue exclusion test of cell viability. Curr Protoc Immunol 2001

16. Osanai K, Higuchi J, Oikawa R, Kobayashi M, Tsuchihara K, Iguchi M, Huang J, Voelker DR, Toga H. Altered lung surfactant system in a Rab38-deficient rat model of Hermansky-Pudlak syndrome. Am J Physiol Lung Cell Mol Physiol 2010;298:L243-L251

17. Kiernan JK. Histological and histochemical methods. In: Theory and practice. 3rd ed. London, New York, New Delhy: Arnold Publisher; 2001. 111-162
18. Suvarna KS, Layton C, Bancroft JD. Pigments and minerals. In: Bancroft's theory and practice of histological techniques. 7th ed. Oxford, UK, China: Churchill Livingstone Elsevier; 2013. 241-242

19. Ellis R. Perl's prussian blue stain protocol. South Australia: Pathology Division, Queen Elizabeth Hospital; 2007.

20. Sun W, Su Q, Cao X, Shang B, Chen A, Yin H, Liu B. High expression of polo-like kinase 1 is associated with early development of hepatocellular carcinoma. Int J Genomics 2014;2014:312130

21. Li L, Xia Y. Study of adipose tissue-derived mesenchymal stem cells transplantation for rats with dilated cardiomyopathy. Ann Thorac Cardiovasc Surg 2014;20:398-406

22. Barker AF, Bergeron A, Rom WN, Hertz MI. Obliterative bronchiolitis. N Engl J Med 2014;370:1820-1828

23. Grommes J, Soehnlein O. Contribution of neutrophils to acute lung injury. Mol Med 2011;17:293-307

24. Shroff A, Mamalis A, Jagdeo J. Oxidative stress and skin fibrosis. Curr Pathobiol Rep 2014;2:257-267

25. Valcheva-Kuzmanova S, Stavreva G, Dancheva V, Terziev L, Atanasova M, Stoyanova A, Dimitrova A, Shopova V. Effect of Aronia melanocarpa fruit juice on amiodarone-induced pneumotoxicity in rats. Pharmacogn Mag 2014;10: $132-140$

26. Lee TH, Sottile J, Chiang HY. Collagen inhibitory peptide R1R2 mediates vascular remodeling by decreasing inflammation and smooth muscle cell activation. PLoS One 2015; 10:e0117356

27. Gumuser G, Vural K, Varol T, Parlak Y, Tuglu I, Topal G, Sayit E. Assessment of lung toxicity caused by bleomycin and amiodarone by Tc-99m HMPAO lung scintigraphy in rats. Ann Nucl Med 2013;27:592-599

28. Selman M, Vicens V, Mendoza C, Montaño M, Ramos C, Romero Y, Molina M. Subsets of fibroblasts show resistance to apoptosis independently of their interstitial lung disease origin. FASEB J 2013;27:1166.4

29. Lee J, Hong EM, Koh DH, Choi MH, Jang HJ, Kae SH, Choi HS. HMG-CoA reductase inhibitors (statins) activate expression of PPARalpha/PPARgamma and ABCA1 in cultured gallbladder epithelial cells. Dig Dis Sci 2010;55:292299

30. Khodayar MJ, Kiani M, Hemmati AA, Rezaie A, Zerafatfard MR, Rashidi Nooshabadi MR, Goudarzi M. The preventive effect of atorvastatin on paraquat-induced pulmonary fibrosis in the rats. Adv Pharm Bull 2014;4:345-349

31. Zhang Y, Dai L, Wu S, Chen P, Zhao S. Atorvastatin attenuates involvement of RhoA/Rho-kinase pathway and NF- $\kappa \mathrm{B}$ activation in hypoxic pulmonary hypertensive rats. Chin Med J (Engl) 2014;127:869-872

32. Chen ZY, Liu SN, Li CN, Sun SJ, Liu Q, Lei L, Gao LH, Shen ZF. Atorvastatin helps preserve pancreatic $\beta$ cell function in obese $\mathrm{C} 57 \mathrm{BL} / 6 \mathrm{~J}$ mice and the effect is related to increased pancreas proliferation and amelioration of endoplasmic-reticulum stress. Lipids Health Dis 2014;13:98

33. Ghasemi N. Therapeutic effects of adipose derived mesenchymal stem cells on remyelination process in inflamma- 
tory demyelinating diseases. J Histol Histopathol 2015;2:8 34. Abd El Azeem AF, Al-Ahmadyb HM, Abdul Rahmana MA, Abdel Hameed MA, Shaalan OF. Angiogenesis induced by autologous whole bone marrow stem cells seeded on collagen scaffolds in silicone nerve tubes. An experimental study. Tanta Dental J 2014;111:227-234

35. Linero I, Chaparro O. Paracrine effect of mesenchymal stem cells derived from human adipose tissue in bone regeneration. PLoS One 2014;9:e107001

36. Castiglione F, Hedlund P, Van der Aa F, Bivalacqua TJ, Rigatti P, Van Poppel H, Montorsi F, De Ridder D, Albersen $M$. Intratunical injection of human adipose tissue-derived stem cells prevents fibrosis and is associated with improved erectile function in a rat model of Peyronie's disease. Eur Urol 2013;63:551-560

37. Wang WW, Li ZZ, Wang W, Jiang Y, Cheng J, Lu S, Zhang JY. Enhanced renoprotective effect of HIF-1 $\alpha$ modified human adipose-derived stem cells on cisplatin-induced acute kidney injury in vivo. Sci Rep 2015;5:10851

38. Albersen M, Berkers J, Dekoninck P, Deprest J, Lue TF, Hedlund P, Lin CS, Bivalacqua TJ, Van Poppel H, De Ridder D, Van der Aa F. Expression of a distinct set of chemokine receptors in adipose tissue-derived stem cells is responsible for in vitro migration toward chemokines appearing in the major pelvic ganglion following cavernous nerve injury. Sex Med 2013;1:3-15

39. Ding Z, Huang H. Mesenchymal stem cells in rabbit meniscus and bone marrow exhibit a similar feature but a heterogeneous multi-differentiation potential: superiority of meniscus as a cell source for meniscus repair. BMC Musculoskelet Disord 2015;16:65

40. Williams AR, Hare JM. Mesenchymal stem cells: biology, pathophysiology, translational findings, and therapeutic implications for cardiac disease. Circ Res 2011;109:923-940 